\title{
GAIA Level 3 Major Internal Structural Defect
}

National Cancer Institute

\section{Source}

National Cancer Institute. GAIA Level 3 Major Internal Structural Defect. NCI Thesaurus. Code $\mathrm{C127963.}$

GAIA Level 3 Major Internal Structural Defect is defined by three criteria: first, the defects are prenatal in origin; second, the defect(s) affect (or have the propensity to affect) the health, survival, or physical or cog nitive functioning of the individual; third, for a live birth, alterations in the internal anatomy must be present at the time of live birth, must persist beyond the immediate peripartum period unless surgically repaired, and must either a) Require documented confirmation of a diagnosis made by a clinician with some experience diagnosing congenital anomalies; OR b) Confirmation of a diagnosis using either individual (ICD-9/ICD-10) codes or as part of an ICD-9/ICD-10 code based algorithm, for which the outcome (individual code or algorithm) has been validated. 